\title{
Preparation and Description of Potentiometric Electrode for the limitation of Sulbutamol Sulphate
}

\author{
Mohauman Mohammad Majeed AL-Rufaie* , Zahraa Yosif \\ Motaweq $^{* *}$
}

Kufa University, College of Science, Chemistry Department, Iraq

E-mail: mohaumanmajeed@ yahoo.com or

muhaimin.alrufaie@uokufa.edu.iq

, * Kufa University - College of Science, Biology Department, Iraq,

E:Mail (zahraayosif@uokufa.edu.iq)

\begin{abstract}
:
A new sulbatamol sulphate SBS membrane electrode was prepared that utilizing for its determination; depend on the forming of the association complex ion of sulbatamol sulphate by the phosphotungstate counter anion deposed in poly vinyl chloride PVC polymer, by use a (Di-n- Octyl Phenyl Phthalate)(Dopp) as the plastizier substance, in membrane.The features properties as well as the behavior of it.The new electrode have been elaborated. The concentrations of medicine by utillizing This sensor show a fast, stable, near-Nernstian response in the range $\left(1 \times 10^{-1}-1 \times 10^{-6}\right) \mathrm{mol} / \mathrm{L}$ were determined with correlation coefficient of about $(\mathrm{r}=0.9991)$ and with of a relative standard about 0.416 additionally deviation relative standard error of $1.710 \%$. The nernast linearity slop was founded and it is equal to $28.9 \mathrm{mV} /$ decade and the detection limit was $4.1 \mathrm{x}$ $10^{-6} \mathrm{~mol} / \mathrm{L}$.

The electrode selectivity coefficient $\mathrm{K}_{\mathrm{i}, \mathrm{j}}$ was calculated, in the existence of several interferences cations with confirmed medicine solutions.

It was found the $\mathrm{pH}$ range response is in the range of $(3-7)$, with the response time of $(30-116)$ sec. for various concentrations at room temperture, the lifetime for electrode was found to be more than 21 days. The electrode was successfully used for potentiometric limitation of sulbatamol sulphate in several pharmaceutical drugs by using direct potentiometry.
\end{abstract}

Keywords: new, sulbatamol sulphate, membrane electrode, utilizing for determination

Introduction :

Salbutamol sulphate (SDS) Drug is including the IUPAC structure RS-[4-[2(tert-butylamino)-1-hydroxyethyl]-2-(hydroxymethyl)phenol] sulphate Fig(1). The drug was pertinence to the medicines family renowned wit adrenergic bronchodilators. The medicines in the Adrenergic bronchodilators are breathed in during the mouth to make bronchial tubes are opening up the (air passages) in the lungs. The remove cough, shotness of breath, wheezing, as well as confused breathing with growing the air flow in the bronchial tubes of [1].<smiles>CCCCNC[C@H](O)c1ccc(O)c(CO)c1</smiles> 


\section{Fig.(1) The chemical structure of salbutamol}

Salbutamol (SBS) is utilized to treat or block bronchospam in asthma patient bronchitis emphysema as well as another lung illnesses. The SBS medicine is too utilized to block wheezing cased by practice - actuated bronchospam[2].Soluble freely in water, practically insoluble or so slightly soluble in ethyl alcohol (96\%) too it is soluble in the methylene chloride.

Some of various approaches of analyses have been informed for limitation of SBS inclusive (HPLC) high performance liquid chromatography [3-9] are time consuming, boring demand special as well as costly apparatus., aside from every one the reported HPLC approaches are comparatively insensitive. Other chromatographic approaches, thin-layer chromatography [10], though unpretentious than HPLC approaches is too minimal sentient with the linear domain being $20-580 \mu \mathrm{g} \mathrm{ml}^{-1}$. The non-chromatographic approaches like spectrophotometry (derivative ultraviolet) $[11,12]$ capillary electrophoresis [13] as well as a.c. oscillopolarography [14] are too comparatively intricately in terms of examination approach or instruments desired for analyses. The extreme vastly uitilized procedure for the salbutamol assay in dose forms has been visible spectrophotometry; approaches depended on like diversified reactions as redox [15,16], chelation after reduction [17], oxidative coupling [18,19], diazotization as well as coupling [20,21], nitration, nitrosation,nitration followed the formation of Meisenheimer complex formation additionally formation charge-transfer complex [22-25] are literature founded.

The sensors by the potentiometric membrane have been vastly utilized in pharmaceutical analyses [26-30 ]. The ion-selective electrodes which are selective to a diversity of the drugs ion have attracted mounting benefit because of their potential utilize in pharmaceutical analyses [31-33]. The benefit features of (ISEs) ionselective electrodes are simplicity, shortened measurement low cost, time, adequate precision as well as accuracy, wide analytical range, adequate detection limits, additionally particularly the capacity to measurement the action of different drugs selectively, as well as in maximum states, without before secession of the drug of benefit from the formularization matrix in chromatic or bleary samples. These make the potentiometry by ISE completely appealing for pharmaceutical analyses [34-35]. In this study we characterize a easy PVC membrane sensor for the of Description Salbutamol (SBS) as potentiometric mannaer in pharmaceutical preparations. The electrode utilized in this study was synthetic from PVC liquid-plasticized as well as was established on a water-insoluble salbutamol-phosphotungstate ion pair as an ioninterchanger.

\section{Experimental \\ Instrumental:}

pH-meter Knick-Digtal (pH-meter and E mv measurments ) England. Calomel Reference Electrode, Gallinkamp, IE-Electrode, USA. Silver-Silver chloride Electrode ,Magnetic Stirrer, Orion Research-USA, Gallinkamp England. Sensitive Balance, Sortoris,W.Germany.

Reagents: All chemicals were used with highly purified and equipped by a Merck,Aldrich and Fluka companys,

The following solutions were prepared in Table(1)

Table (1) Preparation of standard solutions

\begin{tabular}{|c|c|c|}
\hline Materials & Puitry & Campany \\
\hline Salbutamol sulphate & $99 \%$ & SDI(IRAQ) \\
\hline pvc & $98 \%$ & BDH \\
\hline phosphotungstate acid & $90 \%$ & BDH \\
\hline
\end{tabular}




\begin{tabular}{|c|c|c|}
\hline DOPP & $99 \%$ & BDH \\
\hline THF & $75 \%$ & BDH \\
\hline
\end{tabular}

\section{Membrane Electrode Preparation :}

the selective membrane was prepare by using the Mixed Method, where a mixture of $0.006 \mathrm{~g}$ of active ingredient phosphotungstate acid $0.125 \mathrm{~g}$ of plasticized substance (DOPP). And $0.03 \mathrm{~g}$ of polyvinyl chloride (PVC), then dissolve the mixture in the amount of tetrahydrofuran (THF) needed for the magnetization and move the mixture with a magnetic motor to obtain a homogeneous solution .viscous for (7-8) hours[33]

The solution is poured into the glass casting mold (glass cylinder 30-35) attached to a glass plate. The mold is covered with a number of filter papers and a suitable weight for 48 hours to evaporate the solvent and obtain a transparent, homogeneous membrane that facilitates the peel of the glass plate. So that a number of discs can be cut from it (secondary membranes) whose thickness $(0.1$ 0.5 ) is by the seal of the plugs used in the electrode industry [34].The silver-silver chloride electrode is connected to the end of a wire covered with a dielectric to a potentiometer. That is making the anode electrode is used for the cell. This design is arranged with a $25 \mathrm{~mm}$ silver wire with the internal conductor that ends with a wire connected to a voltmeter. the silver wire was pressed in a spiral shape[35]. This wire is then immersed in the inner filling solution consisting of Salbutamol (0. 1) $\mathrm{mol} / \mathrm{L}$. One of the ends of the PVC tube is immersed in a THF solvent and the tube is held vertically on a glass plate. This process is repeated several times to obtain a flat end. Disc is then cut off from the prepared membrane using Cork Borer cork diameter equal to the outer diameter of the PVC tube containing the internal / $\mathrm{AgCl}$ and MLA solution and using forceps this disc is affixed to the end[32] .The other end is connected to the glass tube bearing the internal reference .pole and the internal filling solution which fills the tube to about three sheets The electrode was eventually contingent for $24 \mathrm{~h}$ by dampness in a $0.05 \mathrm{M}$ Salbutamol sulphate solution and this process is a process of homogenization of the membrane of the electrode and saturation solution solution concentration equal to the concentration within the membrane, and then there is a regular exchange of ion from the external solution to the membrane, and then to the internal solution and vice versa [34].the response of selective electrodes to ions depends on the equilibrium between a single type of ions under study during the phase .separation between the model solution and the electrode membrane The response to this response is called Nernstion response, which is proportional to the ion charge under study, so the change in the selective electrode voltage was studied. The response was linear within the range of concentrations $\left(1 \times 10^{-1}-1\right.$ $\left.\mathrm{x} 10^{-6}\right)$ at $25^{\circ} \mathrm{C}$. When the modification in the voltage of the electrode $(\mathrm{E} \mathrm{mV})$ vs. pSBS was found, the regression of the linear nirnest fraction was equal to 28.9 $\mathrm{mV} /$ decade $\mathrm{mV} / \mathrm{As}$ shown in figure (3). This indicates that the drug ion allows the exchange of ions that dissolved in the solution through the membrane ..containing the active substance[32].

Emf Measurements: whole emf mensuration were completed with the next composition: $\mathrm{Ag} / \mathrm{AgCl}$ /internal solution,0.1 SBS+/PVC selective membrane/test solution/SCE. 
The outward reference electrode was a (SCE) standard calomel electrode covered with an medium salt bridge room including the orignal electrolyte in order to any block transmit of the measuring solution potassium ions[30].

\section{Results and Discussion calibration curve}

The response of selective electrodes to ions depends on the equilibrium between a single type of ions under study during the phase phase separation between the It is known that the regression of this .model solution and the electrode membrane response is called Nernstion, which is proportional to the ion charge under study. Therefore, the change in the selective electrode voltage was studied. The response was linear within the range of concentrations $\left(10^{-1}-10^{-6}\right)$ [31]. The linear nirnest fraction slope was $28.9 \mathrm{mV} /$ decade and is approximated to the theoretical nirnest regression As shown in figure (2). This indicates that the drug ion enters allows the exchange of outside the solution through the membrane containing the active substance.

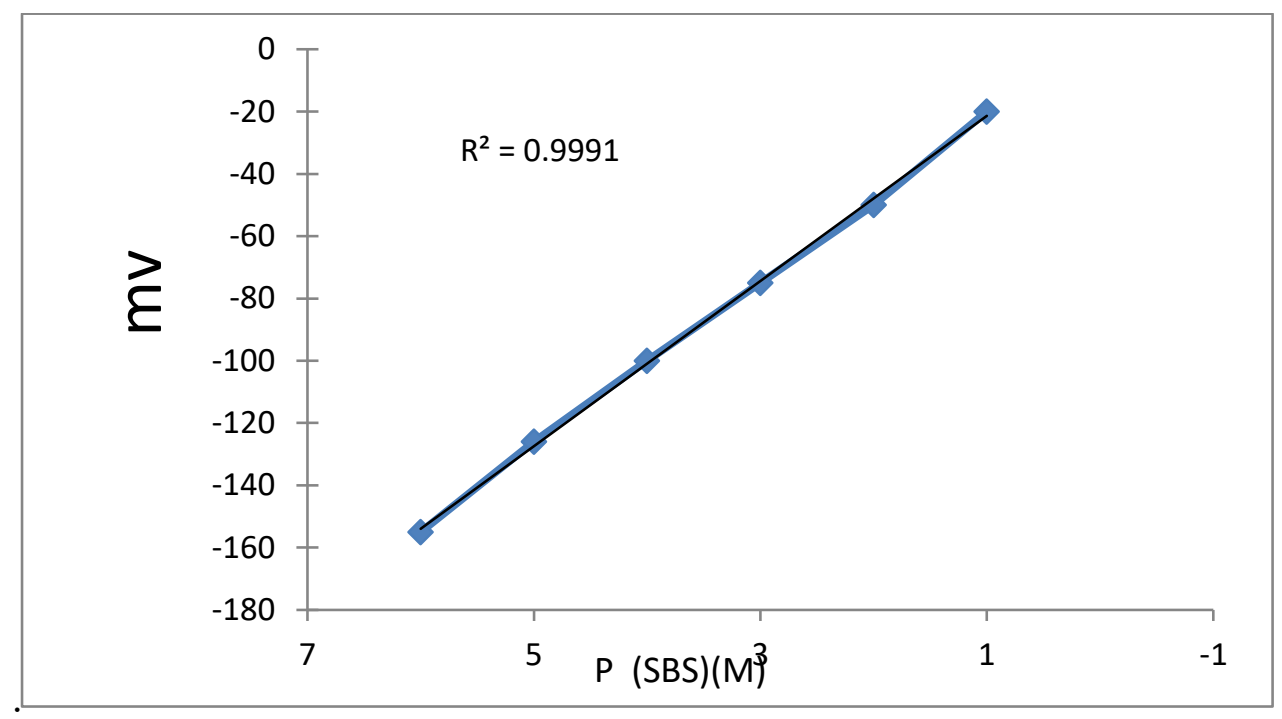

Fig. (2) The calibration curve of salbutamol drug by using (0.1 M) from

\section{Internal filling solution effect} internal filling solution of SBS drug.

The effect of the of the internal filling solution concentration of SBS drug solution was studied on the selective electrode reaction. Concentrations of internal solutions ranging from $(0.1-0.001) \mathrm{mol} / \mathrm{L}[33]$.

The best concentration of SBS drug solution as an internal filling solution for the pole was (0.01) mol / L Tab(2), where it gave the best value of the (nir) slope was $28.9 \mathrm{mV} /$ decade, and the internal fillers $\left(1 \times 10^{-1}, 1 \times 10^{-3}\right) \mathrm{mol} / \mathrm{L}$ showed that no acceptable nirnest response was obtained because the internal solution ions could not produce an appropriate boundary voltage difference between the outer membrane boundary and the internal diameter of the pole, For the ion of the outer solution with the greater concentration of drug ion[35]. 
Table (2) The effect of the internal filling solution concentration on the value of the nernast linearity slop

\begin{tabular}{|c|c|c|c|}
\hline $\mathrm{C} \mathrm{mol} / \mathrm{L}$ & $\mathrm{E} \mathrm{mV}$ & $\mathrm{E} \mathrm{mV}$ & $\mathrm{E} \mathrm{mV}$ \\
& 0.1 & -199 & -170 \\
\hline $10^{-6}$ & -155 & -171 & -140 \\
\hline $10^{-5}$ & -126 & -150 & -122 \\
\hline $10^{-4}$ & -100 & -130 & -110 \\
\hline $10^{-3}$ & -75 & -102 & -81 \\
\hline $10^{-2}$ & -50 & -77 & -58 \\
\hline $10^{-1}$ & -20 & 23 & 19 \\
\hline Slop & 28.9 & & \\
\hline
\end{tabular}

\section{Effect of acidic function}

Figure (3) shows the acidic $\mathrm{pH}$ function effect of the external solution test on the electrode voltage and the use of $0.1,0.01 \mathrm{~mol} / \mathrm{L}$ of drug ion solution. The $\mathrm{pH}$ of the external solution was determined using diluted $\mathrm{HCl}$ solution or dilute $\mathrm{NaOH}$ solution.the prefact range of values of $\mathrm{pH}$ was between $(3-7)$. There is a change in voltage at $\mathrm{pH}$ values greater than (7) or less than (3).

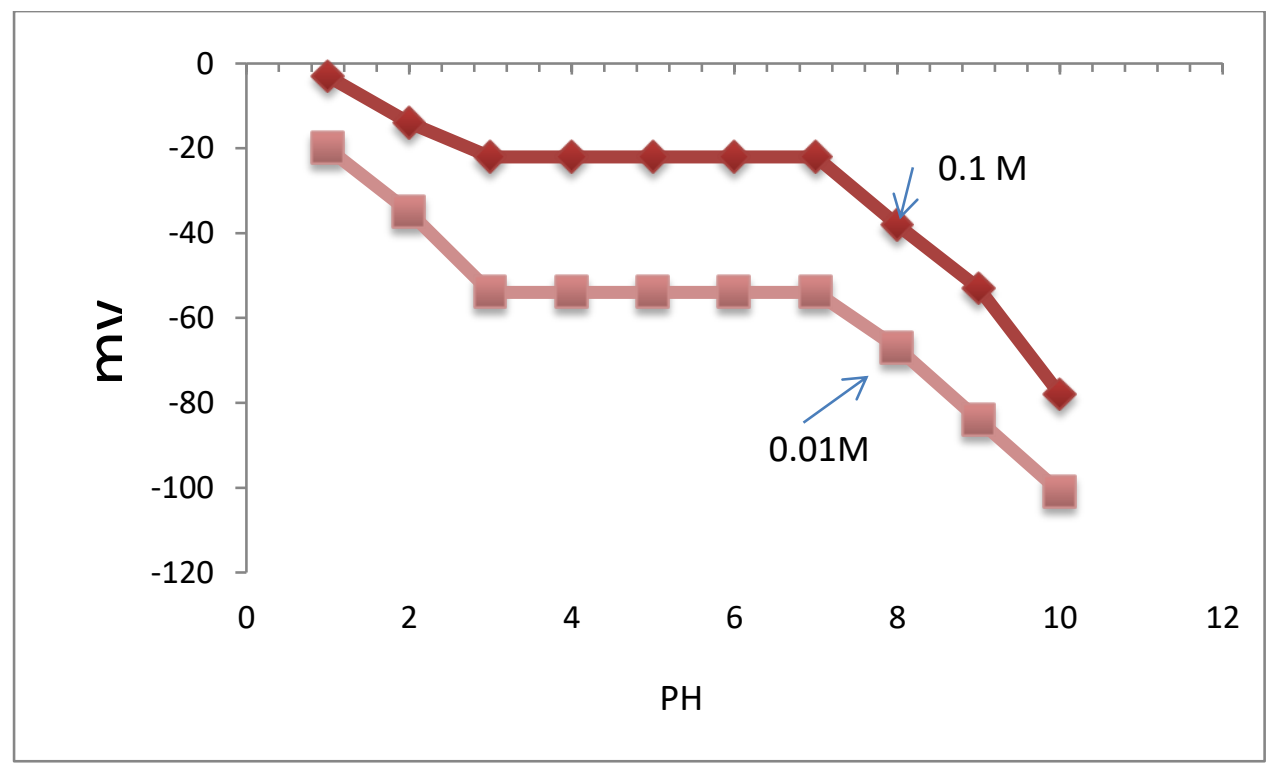

Fig. (3) shows the acidic pH effect value of the external solution test on the electrode voltage by using of $0.1,0.01 \mathrm{~mol} / \mathrm{L}$ of drug solution

$\mathrm{pH}$ values greater than (7) the drug was precipitated pricepetate or less than (3) that happened the acidic errer that prpduced form exchange $\mathrm{H}_{3} \mathrm{O}^{+}$ions with membrane instead of drug ion.that will effect on the mv measurements of electrode[27] . 


\section{The effect of membrane meterials}

The optimal precentge membrane installation acquired by PVC:DOPP: phospohotungstic acid proportion of $0.03: 0.125: 0.006$ (all in gram unit) The membrane potential response at altering concentrations of SBS+ ion, rrefer to a rectilinear domain from $1.0 \times 10^{-6}$ to $1.0 \times 10^{-1} \mathrm{M}$ (Tab 3). The calibration curve slope was $28.9 \pm 0.6 \mathrm{mV}$ decade $^{-2}$ of $\mathrm{SBS}+$ concentration. The detection limit, as given from the two extrapolated segments intersecting of the calibration curve, was $4.1 \times 10^{-6} \mathrm{M}$. The electrode displaied a day-to-day reproducibility of around $\pm 1.0 \mathrm{mV}$ for at minimal at 6 weeks next preparation, while stockpiled in water[30].

Table (3) Optimization of the Membrane Ingredients

\begin{tabular}{|c|c|c|c|c|c|}
\hline \multirow{2}{*}{ No } & \multicolumn{3}{|c|}{ Composition (\%) } & Slope & Linear range [M] \\
\cline { 2 - 4 } & Phos & PVC & Plasticizer & (mV decade ${ }^{-1}$ ) & \\
\hline 1 & 0.001 & 0.020 & 0.012 & 22.1 & $1.0 \times 10^{-3}$ to $1.0 \times 10^{-1}$ \\
\hline 2 & 0.003 & 0.022 & 0.033 & 21.6 & $1.0 \times 10^{-4}$ to $1.0 \times 10^{-1}$ \\
\hline 3 & 0.004 & 0.025 & 0.051 & 23.5 & $1.0 \times 10^{-4}$ to $1.0 \times 10^{-2}$ \\
\hline 4 & 0.005 & 0.028 & 0.090 & 26.5 & $1.0 \times 10^{-5}$ to $1.0 \times 10^{-2}$ \\
\hline 5 & 0.006 & 0.030 & 0.125 & 28.9 & $1.0 \times 10^{-6}$ to $1.0 \times 10^{-1}$ \\
\hline 6 & 0.009 & 0.040 & 0.137 & 27.5 & $1.0 \times 10^{-4}$ to $1.0 \times 10^{-1}$ \\
\hline 7 & 0.011 & 0.045 & 0.145 & 25.3 & $1.0 \times 10^{-4}$ to $1.0 \times 10^{-2}$ \\
\hline 8 & 0.013 & 0.050 & 0.156 & 25.6 & $1.0 \times 10^{-6}$ to $1.0 \times 10^{-4}$ \\
\hline
\end{tabular}

\section{Soaking Effect}

The execution properties of SBS drug sensor were examined as a soaking function of time. For this aim, the electrode was drenched in $10^{-1} \mathrm{M}$ solution of salbutamol as well as the calibration curve ( $\mathrm{E}^{\circ}$ elec. vs. $\mathrm{P}(\mathrm{SBS})(\mathrm{M})$ ) were plotted after 0.0, 0.5, $1.0,2.0,3.0,4.0,5.0,6.0,8.0,12,24$ and $48 \mathrm{~h}$. The prefact timeof soaking was set to be $6.0 \mathrm{~h}$ at room temperature.

\section{Response Time}

Dynamic response time is an serious agent for an ion selective electrode [27]. In this approach , the functional response time was registered by altering solution with various SBS oncentration from $1.0 \times 10^{-3}$ to $1.0 \times 10^{-1} \mathrm{M}$. The genuine potential vs. time vestige that appears the electrode arrives to a short time of the equilibrium response at $30 \mathrm{~s}$. Response Time and Lifetime[35] . The response time for SBS drug was measured using DOPP (30 - 116). The reaction time is inversely proportional to the drug concentration in the outer content due to the stability of the drug ion.The age of the electrode was calculated from time to time, and the pole was 21 days. This was due to the high DOPP's ability to mix with the different dinner components and thus increase the age of the electrode .

\section{plasticizing material Effect (DOPP)}

For the study of plasticizer meterial effect on the electrode response with utilizing different types of plasticizers ,like (DBP ,ONPE,DBPH and DOPP), That the perfact plasticizer material has a significant impact on the electrode response was DOPP and to know this effect must be taken into account the form of this chemical and what is the composition. Figure (4) shows the shape of the plasticizer[28].

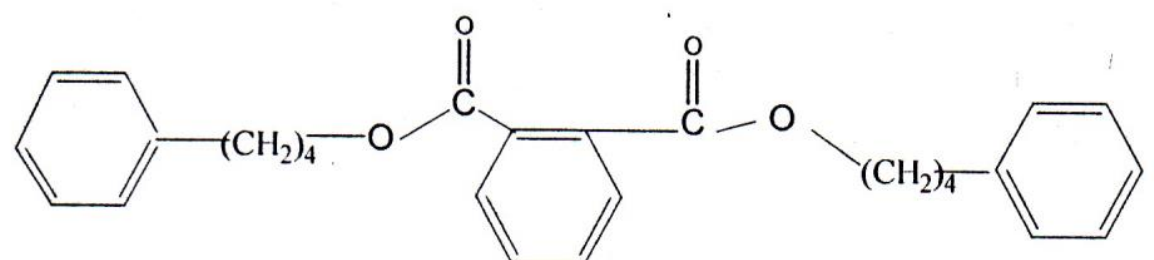




\section{Fig.(4) Chemical composition of plastic material DOPP}

In the form we can observe the ability of the good material to reduce the molecular bonds of Bunmer and reduce the homogenization to block the high permeability resulting from the vinyl aggregates present in the DOPP structure[29].

\section{Selectivity Coefficient $t$ and interference measurement of electrode}

Selectivity Coefficient To measure the effect of overlapping ions on the electrode response, Table 4 appear that the polar response for the ion of drug concerned The presence of each of the interstitial ions referred to in Table 4 is not affected even when the concentration $(0.1) \mathrm{mol} / \mathrm{L}$ is much greater than the measured ion concentration[31]

Where ki, $\mathrm{j}$ was measured using a blending method to measure the interference of other ions with a constant concentration $\left(1 \times 10^{-5}\right)$ of the drug solution. The electrode voltage is measured for a set of standard solutions of interstitial ions and using .equation The following general can be calculated $\mathrm{Ki}, \mathrm{j}$

$\left(\mathrm{E}=\mathrm{E}^{\mathrm{o}}+(2.30 \mathrm{RT} / \mathrm{Zi} \mathrm{F}) \log (\mathrm{ai}+\Sigma \mathrm{Ki}, \mathrm{j}\right.$ aj $\mathrm{Zi} / \mathrm{Zj}$

Where (i) the original drug ion

$\mathrm{j}$ Interlocking ion

(Original shipment)

(Zj Inter-ion charge)

Note that the equation signal is positive if the original ion is charge positive and negative if the original ion is negative charge, the value of $\mathrm{K}_{\mathrm{i} \text {, jpot }}$ can be estimated by several factors, especially the relative motion of ions (i) and (j) during the selective membrane, The equilibrium between the ions in the membrane and the ions in the solution according to the following formula

$$
\mathrm{B}_{\mathrm{j}(\mathrm{sol})}+\mathrm{A}_{\mathrm{i}(\mathrm{mem})} \rightleftarrows \mathrm{B}_{\mathrm{j}(\mathrm{mem})}+\mathrm{A}_{\mathrm{i}(\mathrm{sol})}
$$

When the membrane is very selective towards the Ai ion compared to the interstitial .ion $\mathrm{Bj}$ when the value of $\mathrm{K}_{\mathrm{Ai}, \mathrm{Bj}} \ll<<1$

In general, the increase in the concentration of $\mathrm{Bi}$ in the solution increases the value of $\mathrm{K}_{\mathrm{Ai}, \mathrm{Bj}}$ due to the increase of the ratio of $(\mathrm{aBj} / \mathrm{aAi})$ in solution (12). Through the table we observe the values of $K_{i, j p o t}$ [35]

Table (4) the effect of interference

\begin{tabular}{|c|c|}
\hline Ions & $\mathrm{K}_{\mathrm{i}, \mathrm{j}}^{\text {pot }}$ \\
\hline $\mathrm{Na}^{+}$ & $3.8 \times 10^{-5}$ \\
\hline $\mathrm{K}^{+}$ & $3.1 \times 10^{-5}$ \\
\hline $\mathrm{Cs}^{+}$ & $7.5 \times 10^{-5}$ \\
\hline
\end{tabular}




\begin{tabular}{|c|c|}
\hline $\mathrm{NH}_{4}{ }^{+}$ & $6.1 \times 10^{-5}$ \\
\hline $\mathrm{Sr}^{+2}$ & $5 \times 10^{-5}$ \\
\hline $\mathrm{Ba}^{+2}$ & $4 \times 10^{-4}$ \\
\hline $\mathrm{Ca}^{+2}$ & $2.21 \times 10^{-4}$ \\
\hline $\mathrm{Fe}^{+2}$ & $1.5 \times 10^{-4}$ \\
\hline $\mathrm{Cd}^{+2}$ & $5 \times 10^{-4}$ \\
\hline $\mathrm{Co}^{+2}$ & $3.1 \times 10^{-4}$ \\
\hline $\mathrm{Bi}^{+2}$ & $2 \times 10^{-7}$ \\
\hline $\mathrm{Cr}^{+3}$ & $2 \times 10^{-8}$ \\
\hline $\mathrm{Zn}^{+2}$ & $3 \times 10^{-8}$ \\
\hline $\mathrm{Hg}^{+2}$ & $3 \times 10^{-6}$ \\
\hline $\mathrm{Mn}^{+2}$ & $1 \times 10^{-5}$ \\
\hline $\mathrm{Sn}^{+2}$ & $3.1 \times 10^{-6}$ \\
\hline $\mathrm{Pb}^{+2}$ & $4.1 \times 10^{-5}$ \\
\hline $\mathrm{V}^{+5}$ & $3.1 \times 10^{-8}$ \\
\hline $\mathrm{WO}^{-2}$ & $2.3 \times 10^{-8}$ \\
\hline $\mathrm{Cr}^{+6}$ & $2.3 \times 10^{-6}$ \\
\hline $\mathrm{MoO}^{-2}$ & $4 \times 10^{-7}$ \\
\hline $\mathrm{Ti}^{+4}$ & $4.7 \times 10^{-8}$ \\
\hline $\mathrm{Ag}^{+}$ & $4.1 \times 10^{-6}$ \\
\hline $\mathrm{Al}^{+3}$ & $2 \times 10^{-8}$ \\
\hline $\mathrm{Mg}^{+2}$ & $2.6 \times 10^{-4}$ \\
\hline & \\
\hline &
\end{tabular}

\section{Analytical applications}

This method was applied to measure a certain concentration of SBS drug in the studied SBS pharmecutical preperations, That was taking from S.D.I,Iraq (Butadin (tablets) $(2 \mathrm{mg} / \mathrm{Tab})$ which was using in the prepare of the standard solutins of the drug ) by checking the voltage of the solution including a certain SBS concentration .by the SBS calibration curve

Table (5) shows the comparison of the results using the direct spectral and .gravitational method using the drug electrode

Table (5) Results using spectral method and Direct potentiometry method Concentrated concentration SBS drug mol / liter

\begin{tabular}{|c|c|c|}
\hline $\begin{array}{c}\text { Direct potentiometry } \\
\text { method }\end{array}$ & [36] spectral method & $\begin{array}{c}\text { Concentrated concentration SBS } \\
\text { drug mol / liter }\end{array}$ \\
\hline $9 \times 10^{-4}$ & $4 \times 10^{-3}$ & $1 \times 10^{-3}$ \\
\hline $2.2 \times 10^{-6}$ & $2.2 \times 10^{-6}$ & $1 \times 10^{-6}$ \\
\hline 1.710 & 1.82 & RSD $\%$ \\
\hline 0.416 & 0.630 & RE $\%$ \\
\hline
\end{tabular}

These measurements was average of three tests for each concentration from the drug ion, We observe that the results of the direct method are somewhat similar to the real concentrations of standard of drug ions as compared to the spectral method. They require organic reagents, various chemicals and a device to measure the absorption of the resulting solution, so it is considered a long and boring method when compared to the direct method of. Direct potentiometry method[27]. 


\section{Conclusion}

A new SBS drug selective PVC electrode depended on the compound formation ion pair of SBS - phospohotungstate as well as plasticizer DOPP was advanced. The SBS electrode has a lot of features containing : minimum cost,simpl preparation, that used in the Direct potentiometry method which used for determination of SBS drug as pure substance and in the studied SBS pharmecutical preperations. All properties of the electrode are studied and checked by this paper.

\section{References}

1- Wilson and Gisolds Textbook,"Organic Medical and Pharmaceutical Chemistry", John H Block and john M Beale, Walters Kluwer, London, UK,p. 96 (2004).

2- P.J. Barnes, Pharmaceutical and Therapeutics of Asthma and COPD, Springer verlag Berlin Heidelberg, Germany.p.55 (2014).

3- The British Pharmacopoeia, Her Majesty's Stationery Office

London, p.1151-1156 (1998).

4- The British Pharmacopoeia, Her Majesty's Stationary Office, London, pp.5345,9953,9961,9965 (2009).

5- US Pharmacopoeia XXIIth Rev. ,US Pharmacopoeia Convention, p.1094,2295 (2007).

6- T. L. Bernal, M. J. del-Nozal, H. Velasco and L. Toribio,HPLC versus SFC for determination of salbutamol sulphate and its impurities in pharmaceutical, J.Liq.Chromatography Rel. Technol.19(1996) 1579-1589.

7- S. Ray and A. Bandopadhyay, Reversed phase high performance liquid chromatography determination of salbutamol sulphate in pharmaceutical formulations, Indian Drugs 27(2009) 313-316.

8- R. A. Singh, D. Kumar and A. K. Agarwal,Simultaneous estimation of cetirizine hydrochloride and salbutamol sulphate in pharmaceutical dosage forms by reversed phase high performance liquid chromatography, Pharma Rev.3(2015) 144.

9- A.Takeda, H.Tanaka, T. Shinohara, and I.Ohtake, Detection of lso-plateletactivating factor by high-performance liquid chromatography after reprivatisation with fluorescent fatty acids, J. of Chromatography and Biomedical Application 327(2008) 313 .

10- A.P. Argekar and S.G. Powar, developmebt of estimation of salbutamol sulphate by using HPLC mothed and applications, J. Planar Chromatogr. 11(1998) 254.

11- G. Mukherji and N. Aggarwal, Derivative UV-spectroscopic determination of salbutamol sulphate in the presence of gelatin , Int. J. Pharm.71(1991) 187.

12- N.Talwar, A.K.Singhai, A. K.Shakya, S. Saraf , and N.K. Jain , Colorimetric assay of salbutamol by using new chromogenic reaction, Indian Drugs 28( 1991) 244. 13- K. D. Altri ,application and development of ion chromatography for the analysis of transition metal cations in the primary coolants of light water reactors, J.

Chromatography A634( 1993) 323.

14- L. A.Rodriguez , L. A.Romero, I. E. Tena and M. C. G. A.Coque, development determination of salbutamol in drug forms, J. of AOAC.82(1999) 937.

15- N. P. Sadler and H. Jacobs, Application of the FolinCiocalteau reagent to the determination of salbutamol in pharmaceutical preparations, Talanta 42(1999) 1385.

16- D. Satinsky, R. Karlicek and A. Svaboda,Using on-line solid phase extraction for flow injection spectrophotometric determination of salbutamol, Anal. Chim. Acta 455(2002) 103.

17- T.N.Al-Sabha,Development of spectrophotometric methods for assay of salbutamol in pharmaceutical formulation, J. Edu. and Sci.19(2007) 25. 
18- M. N. Reddy, D. G. Sankar, G. D. Rao and K. Sreedhar, Spectrophotometric determination of salbutamol and terbutaline, East. Pharm. 34(1999) 127.

19-M. Basu and B. Pathak,Estimation of salbutamol sulphate in pharmaceutical formulations, Indian Drugs 28(2009) 109.

20- N. Geetha and T.R. Baggi, Improved spectrophotometric method for the determination of salbutamil sulphate with 3-methyl benzeothiazolin-2-one hydrazone, Microchem J.39(1999) 137.

21- G. G. Mohammed, S. M. Khalil, M. A. Zayed and M. Abd ElHamid El-Shall,2,6Dichloroquinone chlorimide and 7,7,8,8-tetracyanoquino-dimethane reagents for the spectrophotometric determination of salbutamol in pure and dosage forms, J. Pharm. Biomed. Anal. 28(2002),1127.

22- Basavaiah K., and Prameela H.C., Spectrophotometric determination of salbutamol sulphate (SBS) and pyrantel pamoat (PRP) in Bulk drugs and pharmaceuticals ,Chem.Anal. 48(2003) 327.

23- Sadler N. P .and Jacobs H., Application of the Folin-Ciocalteau reagent to the determination of salbutamol in pharmaceutical preparations, Talant 42(10)(1995) 1385 .

24- Al-Sabha T. N., Colorimetric assay of salbutamol in pure form , J.Educ.Sci.19(2007), 25.

25- Patel R.B., Patel A.S. and Pallavi U., New method for the assay of salbutamol in pure form by nitrosation coupling reactions ,Indian Drugs 24(1987) 298.

26- V.V. Cosofret, and R.P. Buck, potentiometric membrane sensors have been widely used in pharmaceutical analysis, Crit. Rev. Anal. Chem. 24 (1993) 1.

27- G.N. Valsami, M.A. Koupparis,and P.E. Macheras, Complexation Studies of Cyclodextrins with Tricyclic Antidepressants Using Ion-Selective Electrodes, Pharmaceut. Res.9 (1992) 94.

28- S.S. Hassan, M.M. Amer, S.A. Abd. El-Fatah, and A.M. ElKosasy, Membrane sensors for the selective determination of fluorouraci, Anal. Chim. Acta 363 (1998) 81.

29- H.Y.Aboul- Enein, X.X. Sun, and C.J. Sun, Ion Selective PVC Membrane Electrode for the Determination of Methacycline Hydrochloride in Pharmaceutical Formulation, Sensors 2(2002) 424.

30- V. K. Gupta,R Prasad and A. Kumar, Dibenzocyclamnickel(II) as Ionophore in PVC-Matrix for $\mathrm{Ni}^{2+}$-Selective Sensor, Sensors 2(2002) 384.

31- S.Yajima,K.Suzuki , and K.Kimura ,Potentiometric Ion Sensors with NeutralCarrier-Type Ion-Sensing Membrances Coated by Biocompatible Phosphorylcholine Polymers, Anal.Sci.16(9)(2000) 899.

32- Z.H.Liu, M.L. Wen, J. Xiong,A Pethidine Selective Polymeric Membrane Electrode Based on Pethidine Silicotungstate,Anal.Sci. 16(8) (2000) 885.

33- V.V.Cosofrot, Membrane Electrodes in Drug Substances Analysis, Pergamon Press, Oxford,London,UK, p.33(1982).

34- J.Koryta, lon-Selactive Electrode, Cambrige University Press, London,UK, p48(1975).

35- Z.M.AL-Mosawy, M.SC. Thesis, Babylon University,Iraq,(2002). 
36 -M.M. AL-Rufaie, A. A. R. Jawad, H. M. Sadiq, Colorimetric estimation for salbutamol sulphate in pure form and in different types of pharmaceutical, Inter. J. ChemTech Res.9(11)(2016) 432. 